\title{
STRUCTURAL ASSESSMENT OF DUBROVNIK CATHEDRAL, CROATIA
}

\author{
JOSIP GALIĆ, HRVOJE VUKIĆ \& DAVOR ANDRIĆ \\ University of Zagreb, Faculty of Architecture, Croatia
}

\begin{abstract}
In this paper a masonry baroque Dubrovnik Cathedral is analysed using the structural assessment method specific for historical buildings. The paper also describes the phases of an integrated approach to obtain accurate structure condition according to visible cracks and its seismic resistance capacity, with possible strengthening techniques. The Dubrovnik Cathedral is a masonry baroque church built in the period from 1671 to 1713 . It was built in the same place where the 12th century Romanesque Cathedral had collapsed in the catastrophic earthquake of 1667. The present Cathedral is a monumental three-nave basilica with a dome over the crossing. In its lifetime the Baroque Cathedral did not show any vulnerabilities until 1979, when it was hit by another earthquake, in which the Cathedral structure was slightly damaged. After the 1979 earthquake the Cathedral was retrofitted from 1981 to 1986 with the aim of increasing the structure capacity under seismic loading. Soon after the retrofitting, cracks on the main columns of the Cathedral started to appear at its base. This was the reason a structural assessment of the Dubrovnik Cathedral was conducted. The activities for the assessment involved historical research based on the analysis of written documents and historical maps, with a focus on the previous major structural changes over the centuries. Visual inspections were undertaken to identify the location and extent of cracks and construction techniques. The assessment also included a geometrical survey of the Cathedral, which was used to develop a three-dimensional finite element model. The numerical simulations led to determining the damage distribution and to identifying the most vulnerable elements. It was used for a comparison between the numerical results and the damage survey. All this led to the conclusion and to identifying the reason for the crack occurrence on the Cathedral structure after the performed strengthening and reconstruction in 1986.
\end{abstract}

Keywords: structural assessment, structural analysis, historical buildings, masonry.

\section{INTRODUCTION}

The subject of this paper is an analysis of the load-bearing structure of the Cathedral of the Assumption of the Virgin in Dubrovnik, hereinafter the Dubrovnik Cathedral. It is a freestanding Baroque Cathedral built between 1671 and 1713. This is the third cathedral built at the same location within the old city of Dubrovnik. Its layout and position can be seen in photographs in Fig. 1. The reasons for this expertise lie in the damages noticed on the main columns of the cathedral, i.e. in their footing, that were observed during the last reconstruction and strengthening of the building between 1981 and 1986. In addition to identifying the cause of the new damaging, an analysis was made of the impact of excavations carried out in the underground of the building between 1981 and 1986 and the execution of the floor slab to create a museum storey in the underground area of the. During archaeological investigations at the time of the cathedral's restoration from 1981 to 1986 excavations were carried out between the foundations where valuable finds were discovered, the most significant find being the remains of a Byzantine basilica. To present the discovered finding, the excavated portion was not restored, instead a bearing floor slab was placed at the cathedral ground level of the newly created underground floor between the church foundations. Similarly, the excavations and finds outside the cathedral at the Bunić Poljana Square were covered. Photographs of excavations and discovered archaeological finds inside the central nave of the cathedral are shown in Fig. 2. 

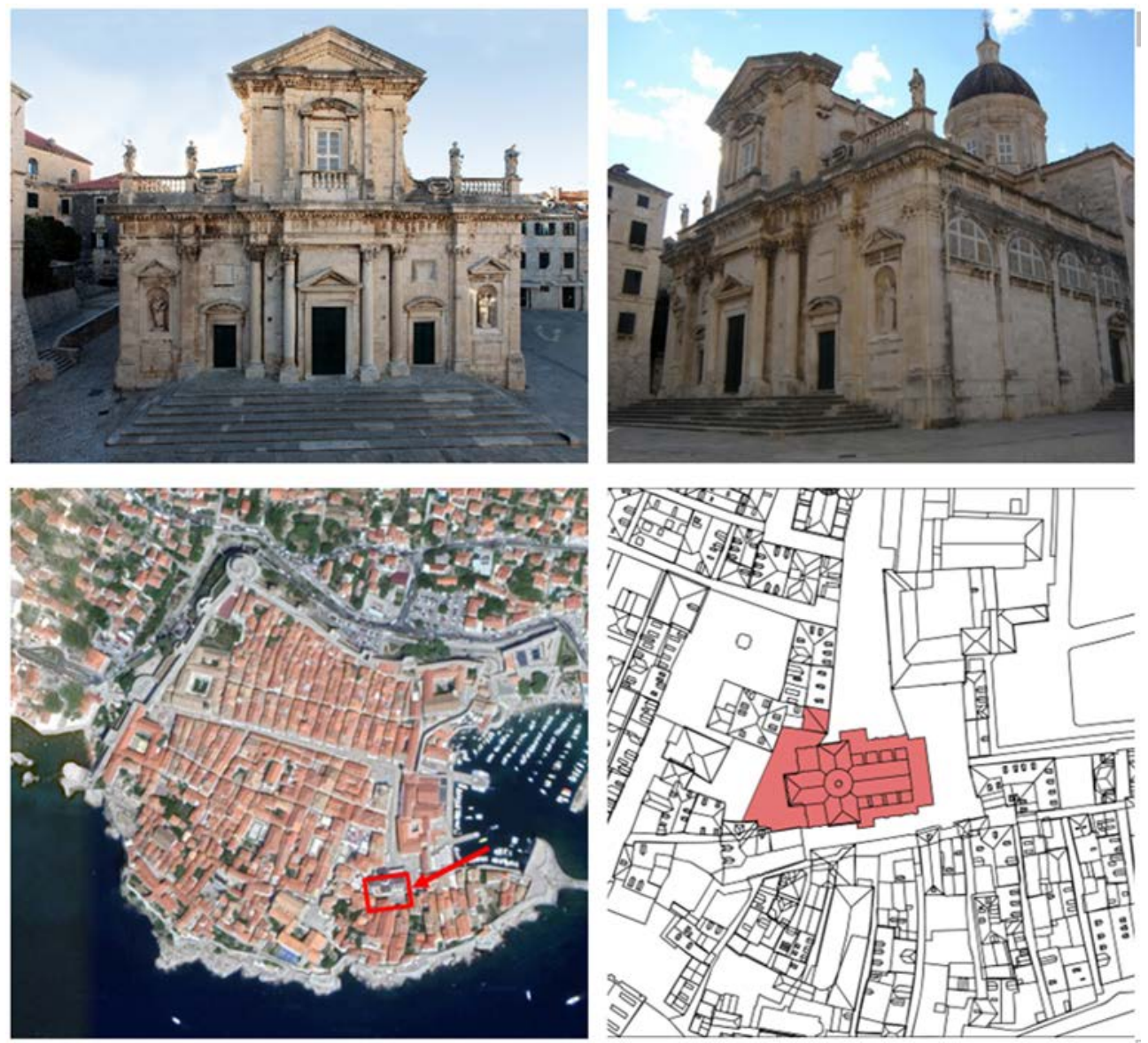

Figure 1: A view of the Cathedral's position and its exterior. (Source: Google Maps and Roman Catholic Diocese of Dubrovnik.)
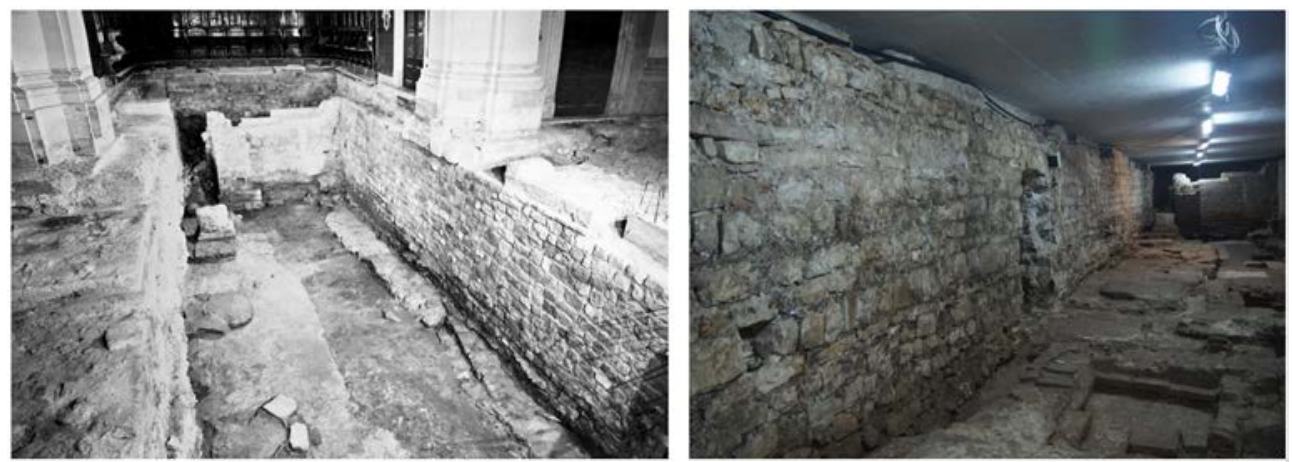

Figure 2: Photographs of the of the central nave underground during excavation and after finished floor slab. (Source: Institute for Restoration of Dubrovnik.) 


\section{HISTORICAL OVERVIEW AND THE DESCRIPTION OF THE CATHEDRAL}

Dubrovnik is a town in the south of Croatia. In 1979 the Old City of Dubrovnik was added to the UNESCO's World Heritage List. It is situated in one of the most seismically active areas of Croatia. On 6 April 1667 Dubrovnik was hit by a catastrophic earthquake in which the Romanesque Cathedral with the neighbouring Archbishop's Palace was completely destroyed. Only segments of longitudinal walls remained partially preserved as confirmed by the records from literature [1]. In June 1667 the Government of Dubrovnik passed the decision about clearing the ruins of the Romanesque Cathedral. The project of construction of a new cathedral had been previously supported by Stjepan Gradić, a distinguished abbot from Dubrovnik. In 1671 he contacted Andrea Buffalini, an Italian architect from Urbino, and commissioned the project. The construction of the cathedral lasted from 1671 to 1713 . During that time, several architects and builders changed. As mentioned, first builders had the idea to use the walls of the Romanesque cathedral for the foundations of a future Baroque cathedral [2]. This idea has been sustained, and on this basis we can see in Fig. 3 the positions of the walls of the Baroque cathedral in relation to the walls of the Romanesque cathedral. In addition to Buffalini, the following builders participated in construction and design: Paolo Andreotti, Pietro Antonio Bazzi, Thomas Napoli, and the last one who completed the cathedral, Ilija Katičić.

The appearance of the load-bearing structure is shown in Fig. 4. The ground plan dimensions are $\mathrm{L}_{\mathrm{x}} \times \mathrm{L}_{\mathrm{y}} \approx 42.0 \times 25.5 \mathrm{~m}$ with the maximum height $\mathrm{H}=36.10 \mathrm{~m}$ (top of the lantern). Looking vertically, the cathedral is divided into three levels. The ground level is at +4.90 , the next level includes terraces above side naves and the chapel which are placed at
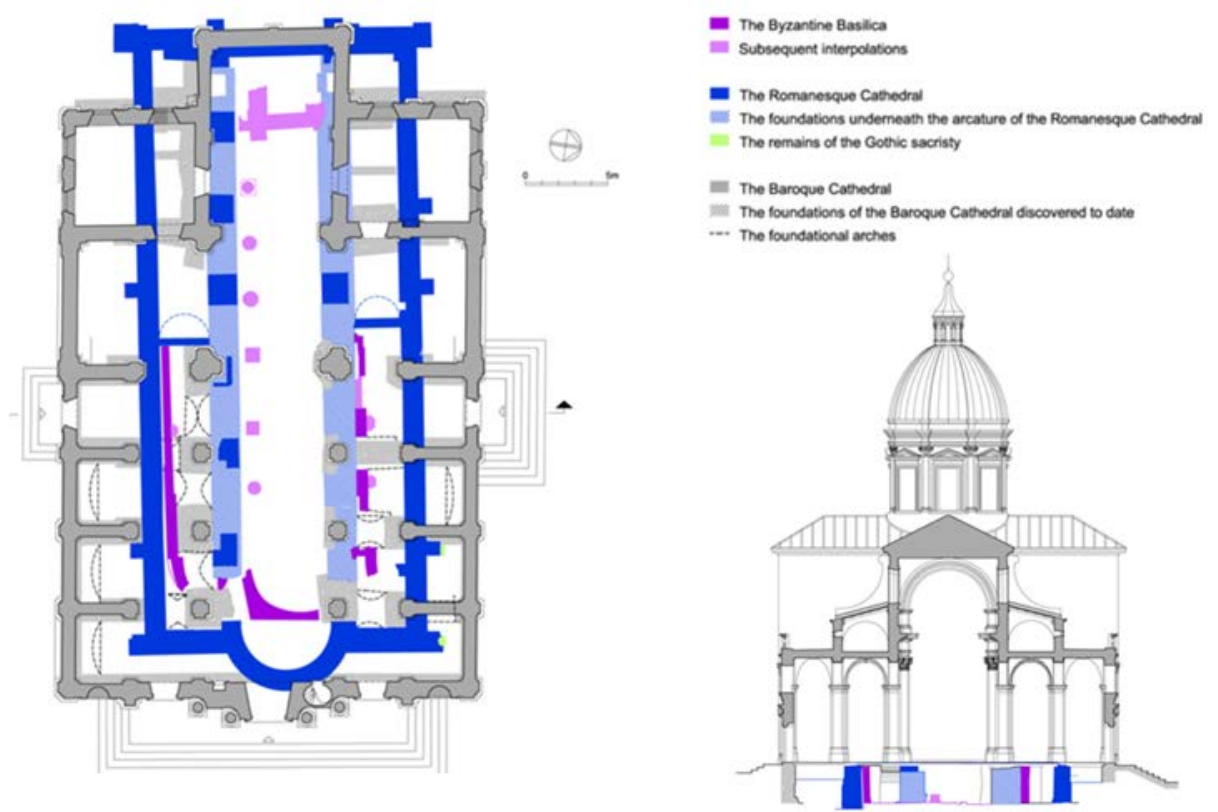

Figure 3: New Baroque cathedral foundations compared to the foundations of the Romanesque cathedral, ground plan and cross section with a view to shrine. (Source: Horvat-Levaj, 2015.) 

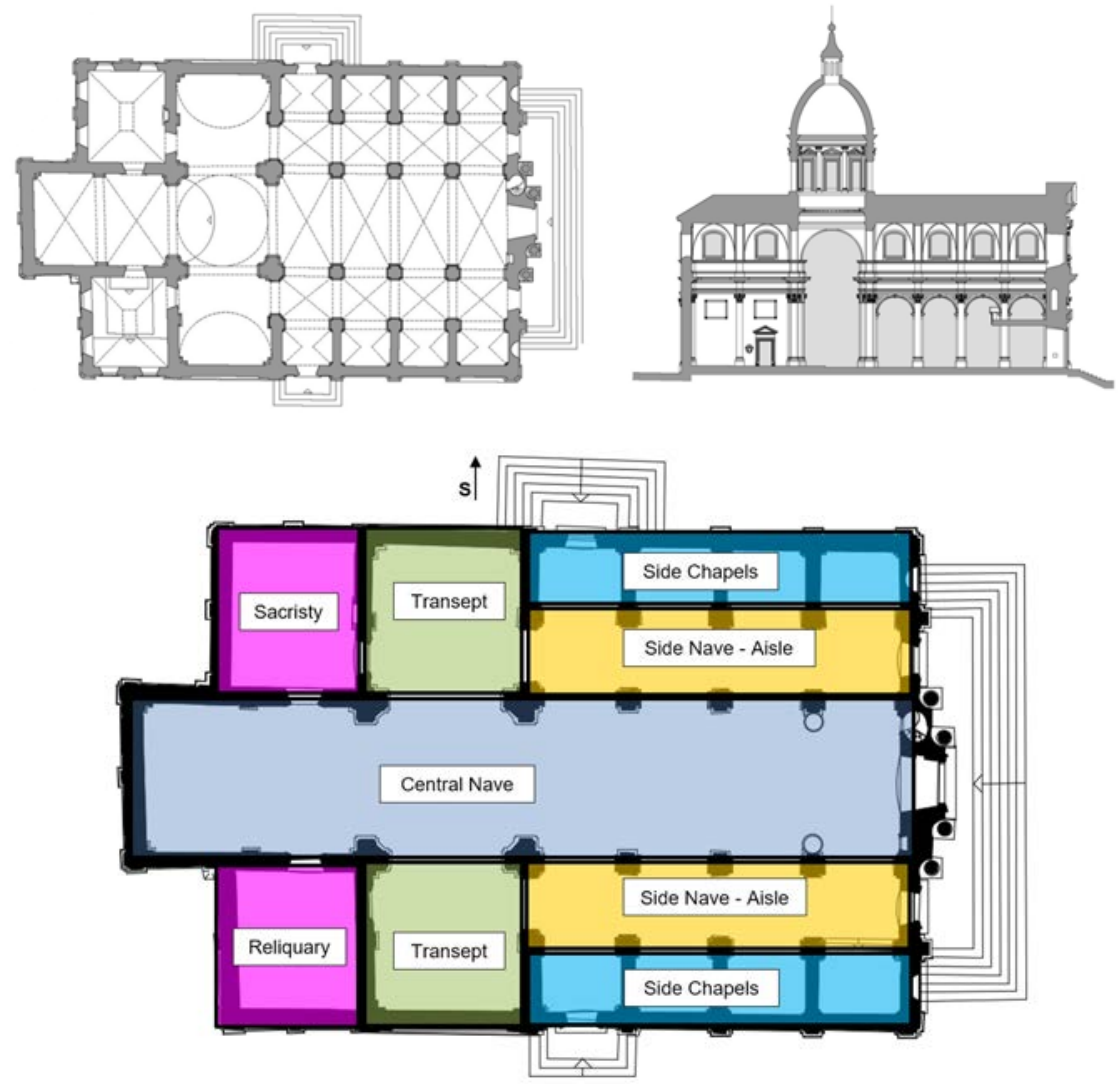

Figure 4: Layout of the built cathedral: ground plan of the floor level (left) and longitudinal section (right), and ground plan of arrangement of different segments of the cathedral (below).

+13.40 . The dome thickness ranges from $\mathrm{t} \approx 40 \mathrm{~cm}$ at the top to $\mathrm{t} \approx 70 \mathrm{~cm}$ at the bottom. It leans on stone walls with thickness $\mathrm{t} \approx 70 \mathrm{~cm}$. The transept ceiling structure is a barrel vault. The vault thickness is $\mathrm{t} \approx 30 \mathrm{~cm}$. The vaults lean on cross walls over arches. The ceiling structure of the central nave consists of cross vaults and it thickness is $t \approx 15 \mathrm{~cm}$. The vault of the sacristy and reliquary is a mirror vault and vault thickness is $t \approx 15 \mathrm{~cm}$. Above the ceiling structure of the vault there is rubble and the floor lining of the terraces. Above the side naves there are cross vaults. The vault thickness is $\mathrm{t} \approx 15 \mathrm{~cm}$ at the vault crown. The vertical bearing structure consists of massive stone walls of carved stone and columns arranged longitudinally and transversally. Longitudinal walls of the central nave in the western area have thickness of $\mathrm{t} \approx 87 \mathrm{~cm}$ and are laid from level +4.9 to +21.4 .

In the eastern part, the longitudinal wall of the central nave does not stretch in full height. Vertically looking, the wall is above the terrace level from +13.4 to +21.4 . At the plane below the terraces to the level +4.9 , it leans on arches and longitudinal nave columns. The wall thickness is $\mathrm{t} \approx 65$ to $75 \mathrm{~cm}$. 


\section{THE 1979 EARTHQUAKE: DAMAGING AND INTERVENTIONS}

\subsection{Earthquake and damaging}

On 15 April 1979 Dubrovnik was hit by a strong earthquake of $7^{\circ}$ magnitude per MercalliCancani-Sieberg scale (MCS). It also caused damages to the Dubrovnik cathedral. These damages were not destructive, but they clearly pointed to the weaknesses of the cathedral and buildings from that time which was elaborately presented in literature [3], [4]. According to the available documents about damage rehabilitation in the Dubrovnik Cathedral that were drawn by Civil Engineering Institute from Zagreb the following damaging was caused by the earthquake: separation of the east wall of the facade and the appearance of vertical cracks in the north and south lateral walls at full height of the walls at the connection with the eastern façade, the appearance of cracks in the vaults, the largest cracks being in the arch of the first span of the central nave, while in other naves the cracks are significantly smaller and disappearing. The cracking was noticed in the dome and some minor cracks in the columns footing. Some documents mention the foundation damaging, but a more detailed analysis states that it is the cracking of lateral walls in the foundation zone underneath and at the joint with the east wall of the façade, which is the result of separation of the east façade together with the foundation from the rest of the building. Earthquake did not endanger the stability of the structure, however, it was necessary to rehabilitate it and to carry out strengthening to reduce the risk of major damaging and collapsing in future earthquakes.

\subsection{Interventions and rehabilitation further to the damaging in the 1979 earthquake}

At the very beginning, a design of the superstructure rehabilitation was developed and the rehabilitation works and strengthening of the existing load-bearing structure was undertaken as follows:

1. All cracks in vaults, walls and arches were injected with a cement-based compound with added bentonite and slaked lime.

2. On the dome, strengthening was carried out using reinforced shotcrete of $5.0 \mathrm{~cm}$ with the added reinforced concrete tie beam of cross section $\mathrm{b} / \mathrm{h}=30 / 20 \mathrm{~cm}$ at the level +29.80 m (Fig. 5).

3. The lantern was also repaired in such a way that the bottom row of the lantern stone was connected to the steel sheets anchored by steel anchors. (Fig. 5).

4. Global strengthening of the load-bearing structure was made by means of ties. Ties were executed in both longitudinal and transversal directions so that the façade walls are connected. In vertical view, ties are executed in four levels. The highest level is at $+21.0 \mathrm{~m}$ which corresponds with the level of the vaults above the central nave. Ties are executed on fascia beam above all walls of the central longitudinal nave and transept. The second level of ties is at $+16.5 \mathrm{~m}$ which matches the level of the lower edge of the window of the main central naves. At the same level, ties in the vault and arch spring were executed to disable shifting of vaults and arches. The third level of ties is at +13.40 at the terrace floor level and they are placed in the closed area above side naves. The fourth level of ties is at the arch spring above side naves and chapels and their purpose is to prevent shifting apart at the arch springs (Fig. 6).

5. At the level $+21.00 \mathrm{~m}$ in the area under the dome, reinforced concrete tie beam was executed (horizontal frame) with cross section $\mathrm{b} / \mathrm{h}=40 / 40 \mathrm{~cm}$. The tie beam is placed directly on the main columns under the dome and all ties that are placed at that level are anchored into it (Fig. 6). 
6. Floor slab execution at the ground floor level further to excavations that started in 1981 for the purpose of the Romanesque cathedral archaeological investigations (Fig. 7).

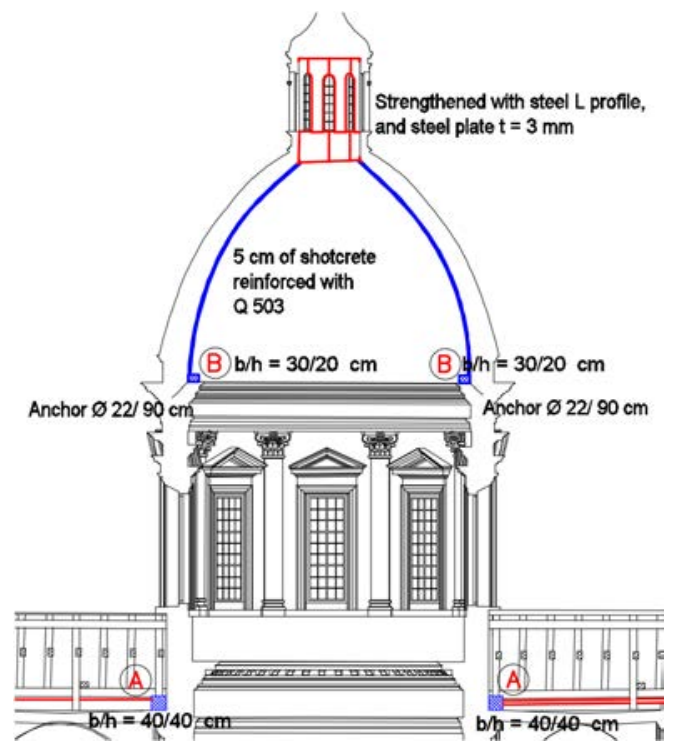

Figure 5: Strengthening of the dome and lantern.
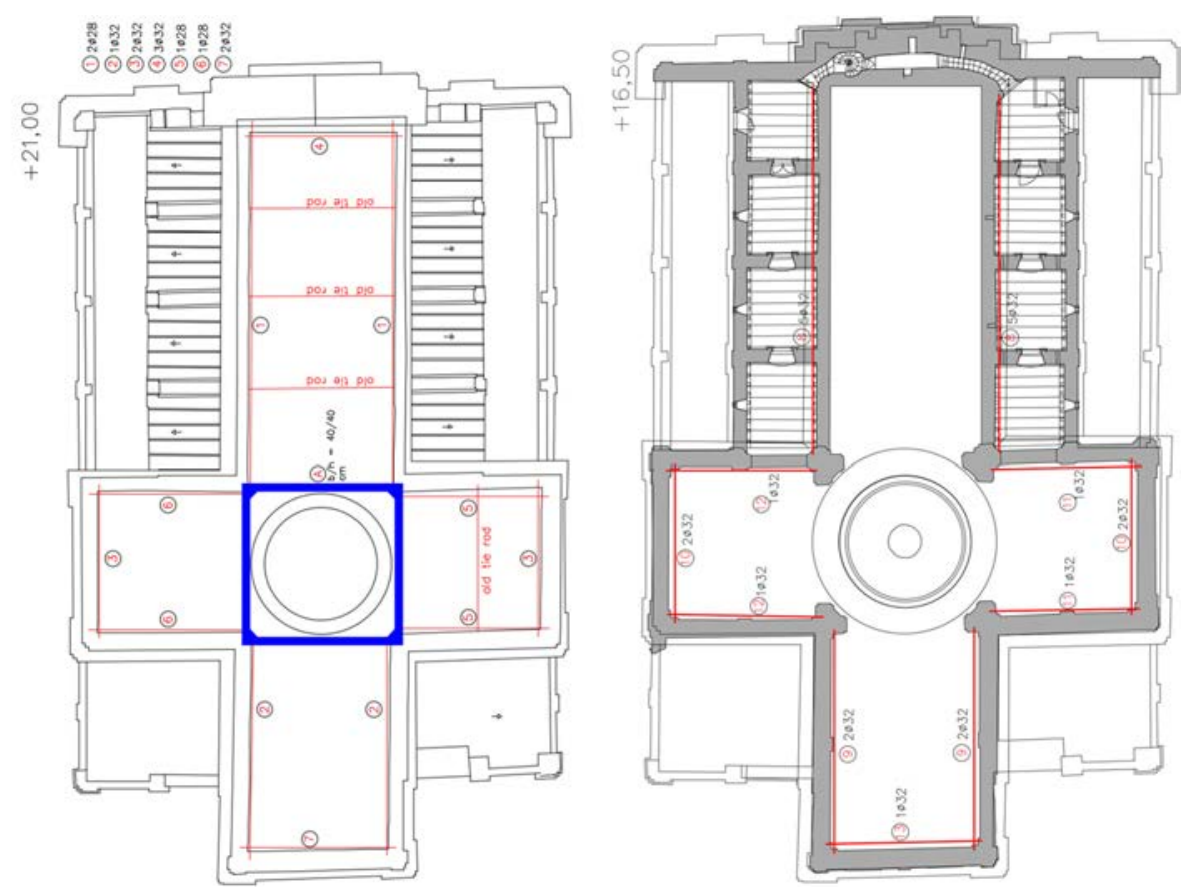

Figure 6: Strengthening at levels $+21.0 \mathrm{~m}$ and at $+16.5 \mathrm{~m}$. 


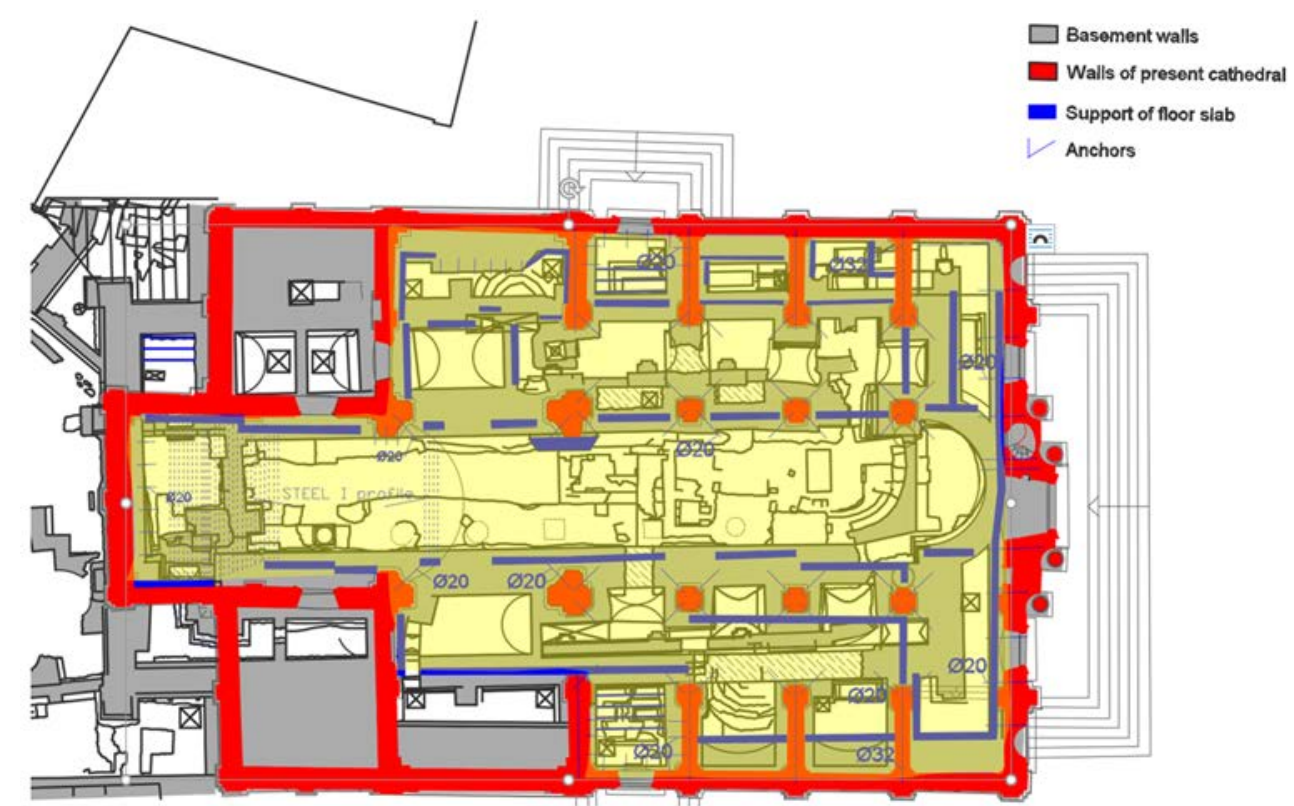

Figure 7: Executed bearing beams, anchors and reinforced concrete slab above the substructure.

Archaeological investigations were completed in 1984 and ultimately resulted in the excavation of almost entire underground of the cathedral between the foundations of the Baroque and the earlier Romanesque cathedral to a depth of $\approx 3.5 \mathrm{~m}$ from the floor level of the cathedral. Extraordinary archaeological finds such as the discovery of the Byzantine basilica in place of the earlier Romanesque cathedral gave rise to the idea of creating an underground museum and therefore the plans to backfill the implemented excavation were abandoned.

In order to establish the museum area in the underground and for cathedral liturgical purpose, a reinforced concrete slab $\mathrm{h}=16 \mathrm{~cm}$ thick separating the two units was constructed at the ground floor level above the underground excavations. The slab was constructed in such a way that it lies on thin concrete beams, which are made on the Romanesque cathedral foundations and foundation strip, to be as inconspicuous as possible, without at the same time leaning on the structures of the Byzantine basilica so that it looks as if it is floating. Practically, a rigid disk was formed with the slab which prevents the shifting of individual vertical structural elements at that level. Also, the beams are connected to the foundations of the Romanesque cathedral via anchor bars and by monolithic connection to the slab. The layout of the engineering solution for the floor slab execution is shown in Fig. 7.

\section{ANALYSIS OF THE EXISTING CRACKS: INVESTIGATION SURVEY}

The reason for this analysis is the damaging of the footing of the main columns. It shall be noted that the said damaging occurred after the reconstruction and strengthening presented in the previous section. The basis for the presentation of the incurred cracks consists in visual inspections of the structure that were carried out twice in 2017 and 2018. During inspection the architectural surveys of the existing condition were used that were prepared by the 
Croatian Conservation Institute in Zagreb, for the superstructure, and by the Institute of Art History in Zagreb for the substructure. During visual inspection cracks were noticed on certain structural elements, but since there were no data about the cracks and damaging that occurred before and after the reconstruction it was difficult to discern which of the cracks were "old" and which were "new". Thus, during visual inspection, all cracks and damaging that were observed were recorded so that their condition could be monitored in future inspections (Fig. 8). Therefore, only the cracks and damaging that can be safely confirmed to have occurred after 1986 are those shown on the columns that are the subject of this analysis. The graphic outline and photographs of the cracks and damaging are shown in Fig. 9.

In addition to visual inspection, the control of the geometry of the cathedral was carried out to determine the accuracy of architectural surveys of the existing condition that were performed by the mentioned institutions. While looking into documents, all available photodocumentation of the reconstruction and interventions carried out in the 1981-1986 period
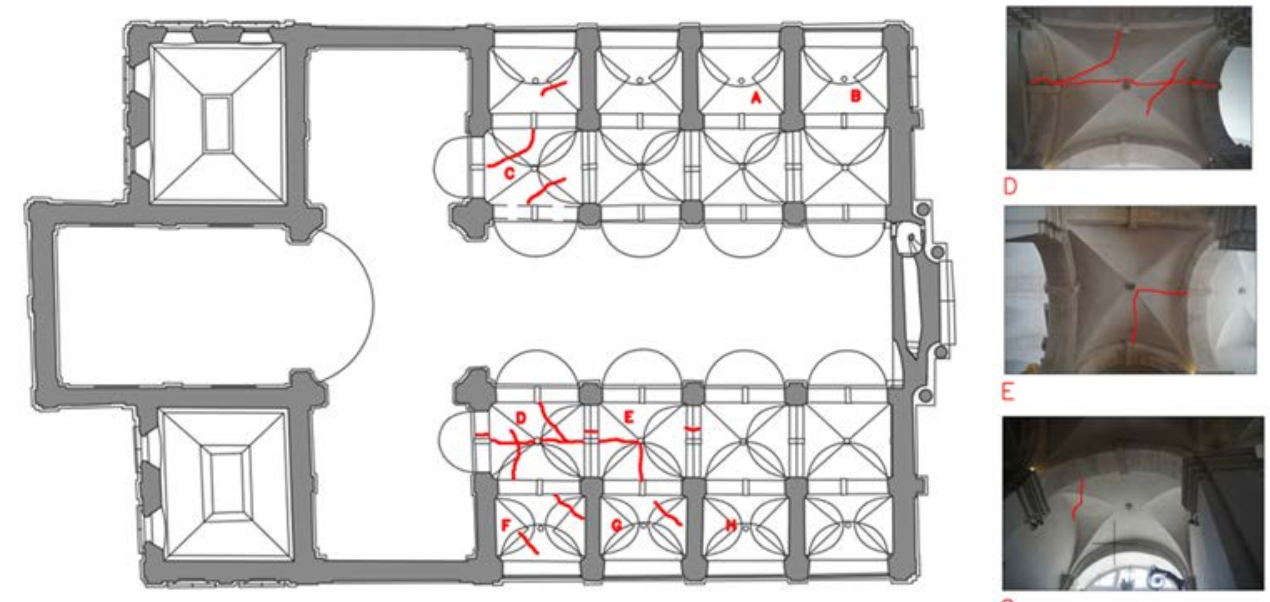

G

Figure 8: Drawing and photographs of characteristic cracks in the vaults.

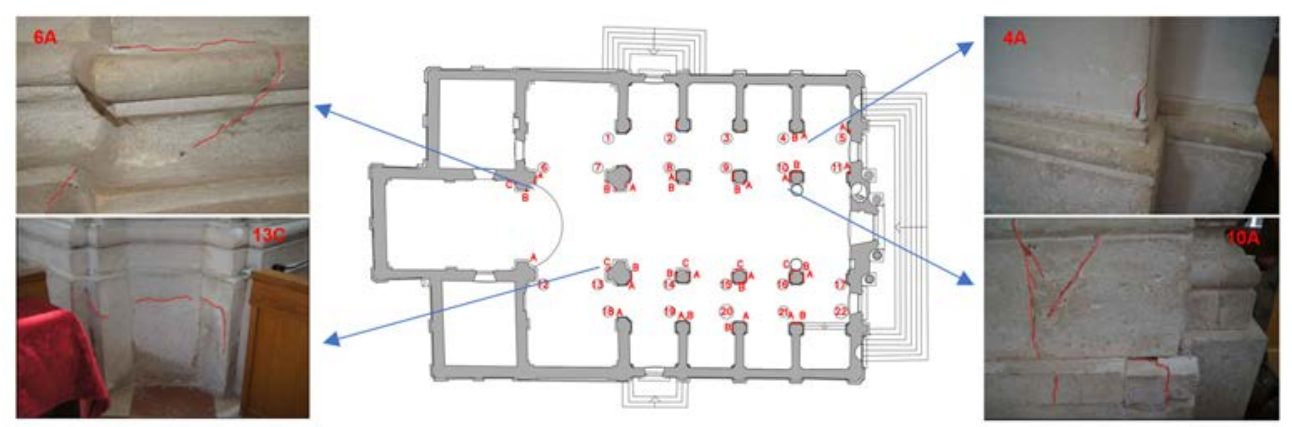

Figure 9: Drawing and photographs of characteristic cracks in the column footing. 
was also studied. The observed details in the photo documentation later directed the research itself, because they identified the possible cause of the damage to the columns on the ground floor. During the visual inspection and investigation works, it was found that the walls were made of stone in lime mortar and as stone masonry of carved crushed stone. Investigations on determining the masonry mechanical properties (compressive and shear strength) were not conducted. The basis for the assessment of the masonry mechanical properties and elements was established based on the available data from testing similar structures and the experience of the researcher of this paper.

\section{STRUCTURAL ANALYSIS}

For the purpose of building analysis, the structure is divided into the roof, the main loadbearing structure and the floor slab. The roof load-bearing structure was calculated in a unique spatial model. In model, defined loads were from structural weight and roof layers, as well as from the snow and wind load according to [6], [7]. Wind and snow loads have proven to be relevant for the load-bearing capacity of structural timber roof elements.

Spatial model of the masonry was made using Rhinoceros programme and based on the architectural survey of the present condition, and the analysis was made in SolidWorks. The existing ties in the modulus were defined as links. Elastic modulus for the static analysis was $\mathrm{E}=2500 \mathrm{MPa}$, and in the dynamic analysis it was $\mathrm{E}=1500 \mathrm{MPa}$. In the first phase a static analysis of the model was conducted. In the second phase a dynamic analysis of the model was performed.

\subsection{Static analysis}

In the first phase, a static analysis of a model loaded with a dominantly permanent load and imposed load was performed (Fig. 10). The loads defined at this stage include the self-weight of the structure automatically calculated by the program, wind load according to [7], weight of the layers on the vaults, weight of the shotcrete on the inside of the dome and also the loads transferred from the roof structure that included permanent dead loads and imposed loads as wind and snow loads. Deformations and stresses caused by loads in static analysis of the structure indicate that the structure has sufficient rigidity and stability. The only areas that need to be reinforced to prevent further cracking of the structure are the arches at the base of the dome and the vaults of the side naves (Fig. 11). These locations of maximum stresses in numerical model coincide with the visible and observed cracks in the cathedral.

The position of cracks in the base of the columns as determined by visual inspection and the comparison with the position of stresses from the numerical analysis did not show any connection (Fig. 12).
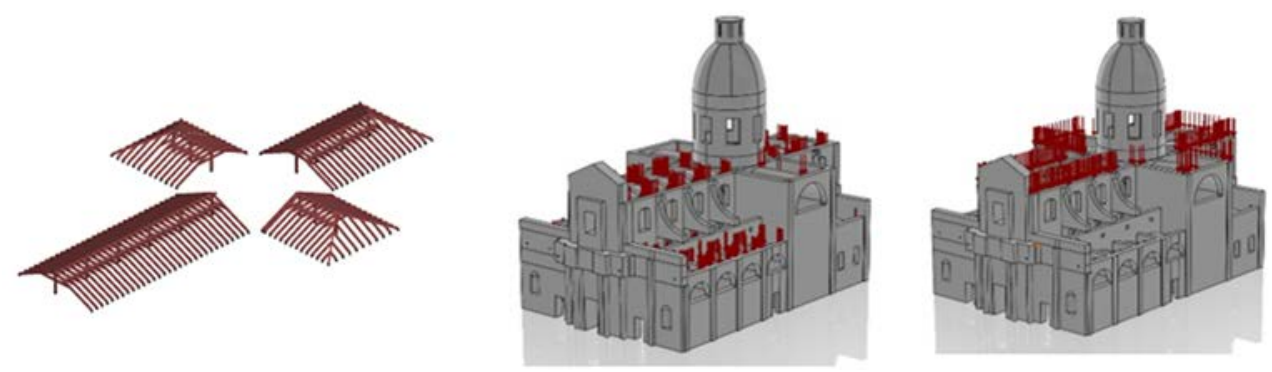

Figure 10: Spatial model roof structure and main structure of Dubrovnik Cathedral. 

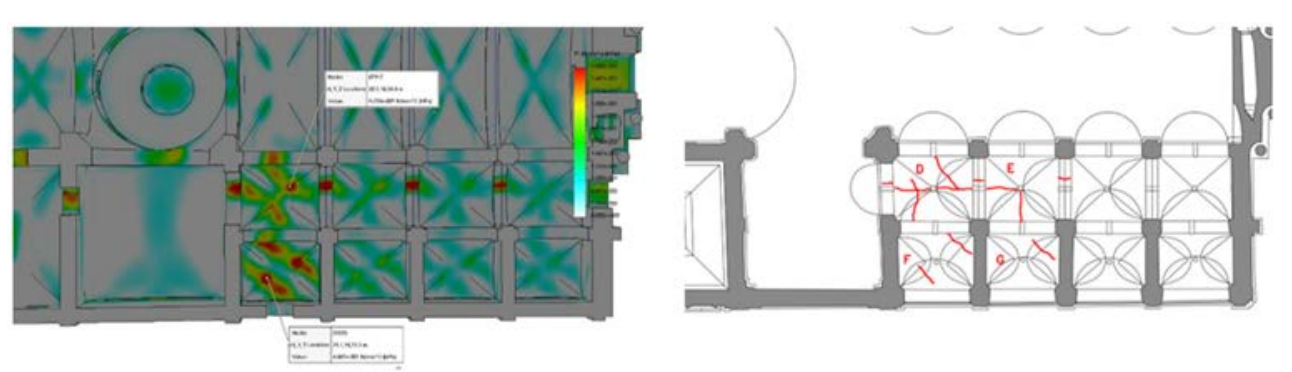

Figure 11: Presentation of tensile stresses of the side nave vaults in numerical analysis (left) and observed crack (right).
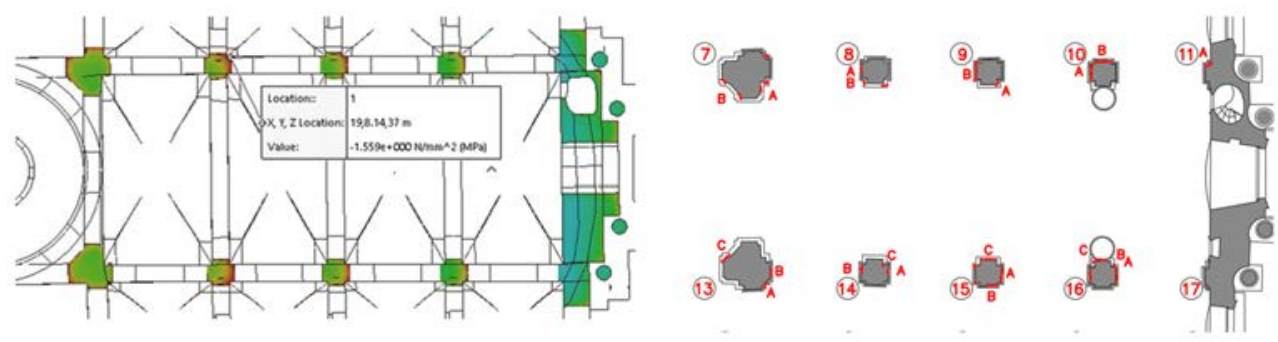

Figure 12: Presentation of the compressive stress of columns in numerical analysis (left) and observed cracks at columns (right).

\subsection{Dynamic analysis}

In the second phase, a dynamic modal analysis was performed. After the modal analysis was performed to determine the basic tones of oscillation of the structure, the horizontal load due to the earthquake action in the longitudinal and transverse directions of the structure was added to the previously defined permanent load. Earthquake was defined for reference return period $\mathrm{T}_{N C R}=95$ years, and corresponding reference peak ground acceleration $\mathrm{a}_{g R}=0.16 \mathrm{~g}$ [8]. The results of the dynamic analysis show that the direction of the earthquake along the length of the cathedral is critical for the structure (Fig. 13). With the combination of the vertical and horizontal forces brought on by the continuous action and earthquake impact, the structure suffers significant stresses and deformations that would certainly cause damaging greater than the one that is currently visible. In order for the structure to resist such action in the future, it is necessary to ensure the transfer of horizontal forces from the vaults to the longitudinal walls. In this respect, it is particularly necessary to reinforce the vaults of the side naves of the cathedral and to ensure the transfer of the said forces to the longitudinal walls, especially to the outer walls of the transept. In dynamic analysis, it is concluded that earthquake action is entirely dominant for global verification. 

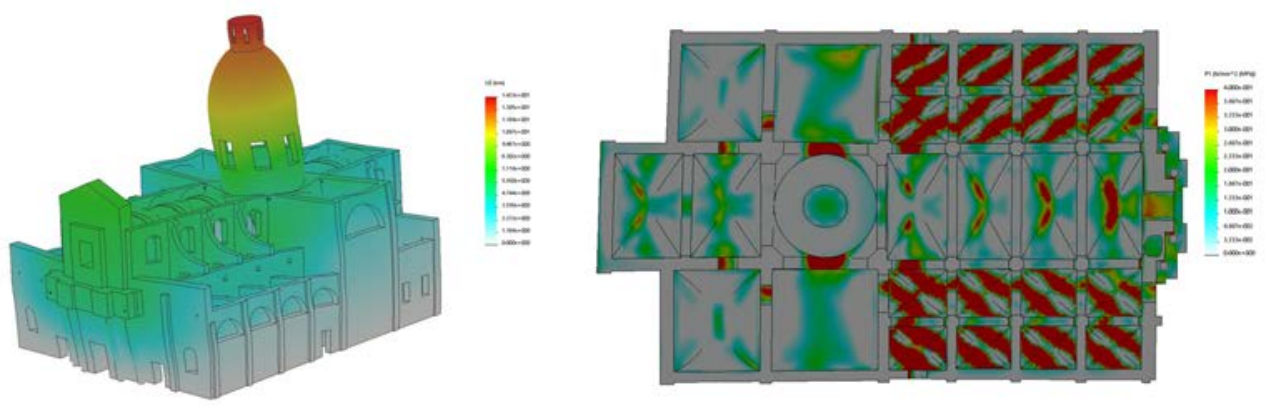

Figure 13: Presentation of deformations resulting from the earthquake impact (left) and tensile stresses in the cathedral vaults (right).

\subsection{Floor slab analysis}

All documentation was examined again, and examining the photographs in the figures and the geometry of the floor slab with the position of its support, it was concluded that the bottom portions of some columns on certain sides had been chiselled off. Furthermore, the photographs of the executed floor slab do not show a visible separation of columns from the floor slab with some elastic material. Further to this, a floor slab numerical model was made. Load on slab was based on permanent load (weight of slab and layers) and imposed load according to [5]. Based on the analysis, negative reactions were obtained, that is, lifting off the slab at the places where the floor slab anchors had been installed. It is confirmed that on location where floor slab is connected with columns, cracks occur at column base. All of this may be seen in Fig. 14.
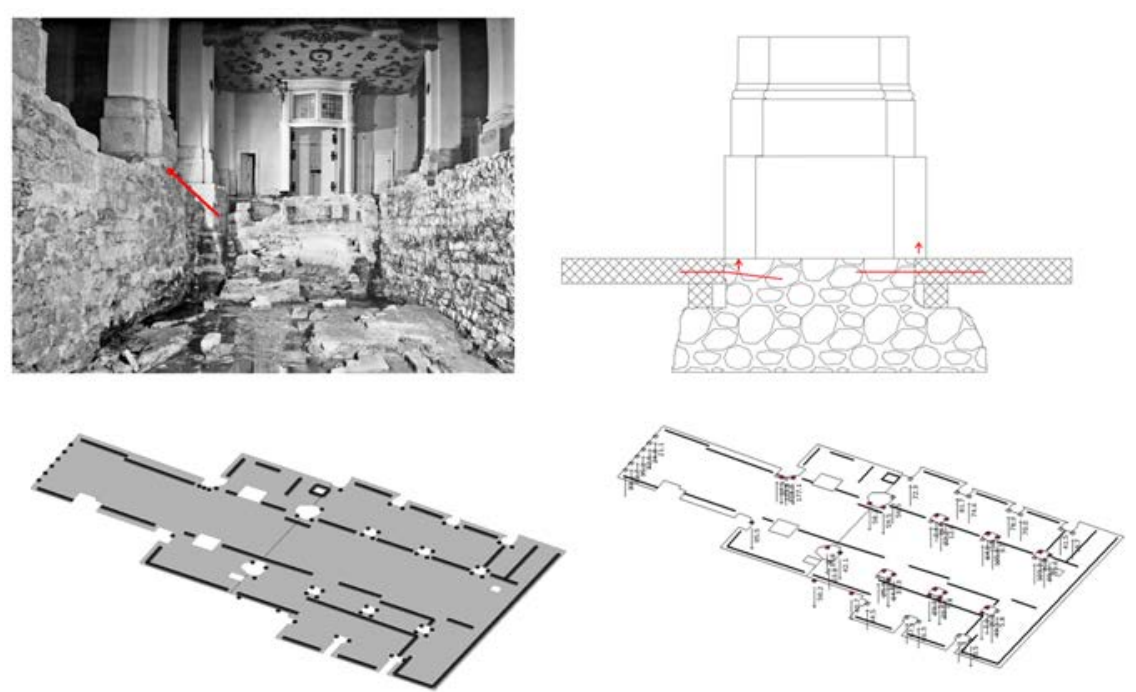

Figure 14: Presentation of the visible location of the secured parts of the columns and the lever effect, and the model of the floor slab on the basis of which the analysis was performed. 


\section{CONCLUSION}

With respect to the analyzes performed, it can be concluded from the static numerical analysis that the positions of the significant stresses in the model at the vault positions corresponded to the observed cracks in the cathedral. However, the positions of the column stresses from the static numerical analysis did not correspond to the positions of the observed cracks, this mismatch was later confirmed by the lever effect of the floor slab. Dynamic analysis has confirmed that it is relevant in terms of maximum stresses, and also that the earthquake action in relation to the imposed load (snow and wind) is relevant for the global structural load bearing analysis. In this respect, it is particularly important to reinforce the vaults of the side naves of the cathedral to ensure the transfer of forces to the longitudinal walls, especially to the walls of the transept and shrine. Realistically, these are the only possible interventions on the additional strengthening of the bearing structure that are acceptable for this type of buildings. The recommended system of strengthening is one of the FRCM systems. In order to prevent further damage to the columns, it is proposed to release the connection of the slab to the columns at critical locations. The said release would be accomplished by cutting the slab and the anchors at the locations where slab lift off.

\section{REFERENCES}

[1] Horvat-Levaj, K., Katedrala Gospe Velike u Dubrovniku, Gradska župa Gospe Velike i Institut za povijest umjetnosti: Dubrovnik i Zagreb, p. 594, 2014.

[2] Horvat-Levaj, K., The Sicilian architect Tommaso Maria Napoli and the Baroque Cathedral of Dubrovnik. Riha Journal, 1(16), pp. 1-32, 2015.

[3] Borri, A. \& De Maria, A., Eurocode 8 and Italian code: A comparison about safety levels and classification of interventions on masonry existing buildings. Perspectives from the Italian Standpoint Workshop, pp. 237-246, 2009.

[4] University of Padova, New integrated knowledge based approaches to the protection of cultural heritage from earthquake-induced risk. http://niker.eu/downloads/. Accessed on: 10 Mar. 2018.

[5] Croatian Standards Institute, HRN EN 1991-1-1: Eurocode 1: Actions on structures. Part 1-1: General actions - Densities, self-weight and imposed loads for buildings, 2012.

[6] Croatian Standards Institute, HRN EN 1991-1-3: Eurocode 1: Actions on structures. Part 1-3: General actions - Snow loads, 2012.

[7] Croatian Standards Institute, HRN EN 1991-1-4: Eurocode 1: Eurocode 1: Actions on structures. Part 1-4: General actions - Wind actions, 2012.

[8] Croatian Standards Institute, HRN EN 1998-1: Eurocode 8: Design of structures for earthquake resistance. Part 1: General rules, seismic actions and rules for buildings, 2011.

[9] Croatian Standards Institute, HRN EN 1998-3: Eurocode 8: Design of structures for earthquake resistance. Part 3: Assessment and retrofitting of buildings, 2011. 